\title{
Diuretic-induced hypokalaemia and surgery: much ado about nothing?
}

\author{
L.J. Restrick, N. Huddy ${ }^{1}$ and B.I. Hoffbrand
}

Whittington Hospital, London N19 and ${ }^{1}$ Anaesthetics Department, Broomfield Hospital, Chelmsford, Essex, UK

There is physiological and clinical evidence that has given rise to concern about the risk of arrhythmias in patients with hypokalaemia. It is known that hypokalaemia, when induced experimentally, potentiates arrhythmias by altering the intracellular/extracellular ionic ratio. ${ }^{1}$ The resulting increase in resting transmembrane potential ${ }^{2}$ and the reduction in atrio-ventricular conduction ${ }^{3}$ facilitate both re-entrant and automatic arrhythmias. ${ }^{4}$ In clinical practice the characteristic electrocardiogram (ECG) changes of hypokalaemia ${ }^{5}$ are seen in up to $80 \%$ of patients with serum potassium less than $2.7 \mathrm{mmol} / 1^{6}$ and ectopic beats are common. ${ }^{7}$ Hypokalaemia causing significant arrhythmias is less well documented, and occurs more often when hypokalaemia is severe or acute. ${ }^{8,9}$

The only well-documented risk of arrhythmias due to mild hypokalaemia is seen in hypokalaemic patients taking digoxin..$^{10}$ There is also circumstantial evidence that hypokalaemia predisposes to arrhythmias during acute myocardial infarction. ${ }^{11-14}$ However, it has never been clearly demonstrated that diuretic-induced hypokalaemia, per $s e$, increases the risk of clinically important arrhythmias. ${ }^{15-18}$ The Multiple Risk Factor Intervention Trial Research Group ${ }^{19}$ found no association between coronary artery disease mortality and hypokalaemia and the Medical Research Council mild hypertension trial ${ }^{20}$ found no significant association between the number of ventricular extra-systoles and serum potassium in patients on long-term thiazides. There is only one small randomized crossover study which found more frequent ventricular extra-systoles and myocardial instability when patients were taking thiazides rather than potassium-sparing diuretics. ${ }^{21}$

The risk of chronic preoperative hypokalaemia due to diuretics remains controversial because of

Correspondence: L.J. Restrick, M.R.C.P., Department of Thoracic Medicine, King's College School of Medicine and Dentistry, Bessemer Road, London SE5 9PJ, UK Received: 25 November 1991 differences in perception of attributable risk for intraoperative arrhythmias. Moreover, serum potassium is not static intraoperatively. Serum potassium is reduced by catecholamines, ${ }^{22}$ by hyperventilation which results in a respiratory alkalosis ${ }^{23,24}$ and by the action of some anaesthetic agents. ${ }^{25}$ Other anaesthetic drugs such as suxamethonium can also cause hyperkalaemia. ${ }^{26}$

Arrhythmias during anaesthesia and surgery, even in normokalaemic patients, are common, ${ }^{27,28}$ although only a small proportion of these arrhythmias are serious. ${ }^{29}$ Certain patient characteristics, such as cardiac disease, poor general medicad condition and age over 70 years, are associate with increased risk of arrhythmia and cardiac complications in patients undergoing non-cardiac operations under general anaesthesia. ${ }^{30}$ Laryngoscopy, intubation, anaesthetic agents, metabolic changes produced by controlled ventilation and surgical manoeuvres may also potentiate arrhythmias. ${ }^{31}$ As a consequence of these other risk factors, and the frequency with which intraoperative arrhythmias are seen, it has been calculated that a controlled study of 8,600 patients would be needed to detect a $50 \%$ increase in mortality due to intraoperative arrhythmias attributable to hypokalaemia. ${ }^{32}$

There are only two controlled studies which address the issue of the risk of preoperative hypokalaemia for intraoperative arrhythmia and compare outcome and events in anaesthetized hypokalaemic patients with normokalaemic patients. In the first study published in 1985 from Las Vegas, ${ }^{33}$ there was no significant difference in incidence of arrhythmia between 88 normokalaemic (serum potassium; 3.5-5 mmol/l) and 62 chronically hypokalaemic patients (serum potassium; $2.6-3.4 \mathrm{mmol} / \mathrm{l})$. The only risk factor associated with intraoperative dysrhythmia was the presence of preoperative dysrhythmia $(P<0.0082)$ and there were no intraoperative arrhythmias requiring treatment. The second larger study reported a series of patients undergoing cardiac or vascular surgery, ${ }^{34}$ and hence considered to be at 
greater risk of intraoperative arrhythmia than the patients in the Las Vegas study. There was, however, no significant difference in either severity or frequency of intraoperative arrhythmias between the 255 normokalaemic patients (serum potassium greater than $3.6 \mathrm{mmol} / \mathrm{l})$, the 152 hypokalaemic patients (serum potassium; $3.1-3.5 \mathrm{mmol} / \mathrm{l}$ ) and the $\mathbf{4 0}$ markedly hypokalaemic patients (serum potassium less than $3.0 \mathrm{mmol} / \mathrm{l})$. Hypokalaemia did not even increase the incidence or severity of ectopy in this study, although frequent and complex ventricular ectopics were more common in patients in congestive cardiac failure or taking digoxin. In both studies the groups were matched for age, cardiac disease and treatment, operative factors and hypoxaemia.

The conclusions from this data were that preoperative hypokalaemia was not a risk factor for intraoperative arrhythmias, which were related to other patient characteristics and preoperative factors. Whilst a low serum potassium may be a marker of increased sympathetic activity or metabolic alkalosis, chronic asymptomatic preoperative hypokalaemia is not a risk factor for intraoperative arrhythmias.

The consensus minimum recommended preoperative serum potassium, at which routine or emergency anaesthesia should be safely undertaken in the absence of cardiac disease or treatment with digoxin, has been $3.5 \mathrm{mmol} / 1 .{ }^{35}$ In the light of these two controlled studies ${ }^{33,34}$ this is overcautious. A chronic serum potassium $3 \mathrm{mmol} / \mathrm{l}$ or above should not alter preoperative and anaesthetic management in patients at low risk of cardiac complications of surgery and anaesthesia and chronic asymptomatic hypokalaemia as low as $2.5 \mathrm{mmol} / 1$ may even be acceptable in these patients. McGovern $^{36}$ in 1988 stated that hypokalaemia in the range 3-3.5 mmol/1 was not an indication for potassium supplementation or postponement of operation and we strongly endorse this view.

\section{References}

1. Vassalle, M. Cardiac pacemaker potentials at different extraand intracellular K concentrations. Am J Physiol 1965, 208: 770-775.

2. Gettes, L.S., Surawicz, B. \& Shiue, J.C. Effect of high K, low $\mathrm{K}$, and quinidine on $\mathrm{QRS}$ duration and ventricular action potential. Am J Physiol 1962, 203: 1135-1140.

3. Fisch, C. Relation of electrolyte disturbances to cardiac arrhythmias. Circulation 1973, 47: 408-419.

4. Helfant, R.H. Hypokalaemia and arrhythmias. Am J Med 1986, 80: 13-22.

5. Surawicz, B. \& Lepeschkin, E. The electrocardiographic pattern of hypopotassemia with and without hypocalcemia. Circulation 1953, 8 (Suppl 4A): 801-828.

6. Surawicz, B., Braun, H.A., Crum, W.B., Kemp, R.L., Wagner, S. \& Bellet, S. Quantitative analysis of the electrocardiographic pattern of hypopotassemia. Circulation 1957, 16: $750-763$.

7. Davidson, S. \& Surawicz, B. Ectopic beats and atrioventricular conduction disturbances in patients with hypopotassemia. Arch Intern Med 1967, 120: 280-285.

8. Harrington, J.T., Isner, J.M. \& Kassirer, J.P. Our national obsession with potassium. Am J Med 1982, 73: 155-159.

9. Anon. Potassium disorders and cardiac arrhythmias. Drug Ther Bull 1991, 29: 73-75.

10. Steiness, E. \& Olesen, K.H. Cardiac arrhythmias induced by hypokalaemia and potassium loss during maintenance digoxin therapy. Br Heart J 1976, 38: 167-172.

11. Duke, M. Thiazide-induced hypokalaemia: association with acute myocardial infarction and ventricular fibrillation. JAMA 1978, 239: 43-45.

12. Hulting, J. In-hospital ventricular fibrillation and its relation to serum potassium. Acta Med Scand 1981, 647 (Suppl): $109-116$.

13. Nordrehaug, J.E. \& von der Lippe, G. Hypokalaemia and ventricular fibrillation in acute myocardial infarction. $\mathrm{Br}$ Heart J 1983, 50: 525-529.

14. Nordrehaug, J.E., Johannessen, K.-A. \& von der Lippe, G. Serum potassium concentration as a risk factor of ventricular arrhythmias early in acute myocardial infarction. Circulation 1985, 71: 645-649.

15. Madias, J.E., Madias, N.E. \& Gavras, H.P. Nonarrhythmogenicity of diuretic-induced hypokalaemia: its evidence in patients with uncomplicated hypertension. Arch Intern Med 1984, 144: 2171-2176.

16. Holland, O.B., Kuhnert, L., Pollard, J., Padia, M., Anderson, R.J. \& Blomqvist, G. Ventricular ectopic activity with diuretic therapy. Am J Hypertens 1988, 1: 380-385.

17. Papademetriou, V., Burris, J.F., Notargiacomo, A., Fletcher, R.D. \& Freis, E.D. Thiazide therapy is not a cause of arrhythmia in patients with systemic hypertension. Arch Intern Med 1988, 148: 1272-1276.

18. Orme, $M$. Thiazides in the 1990 s; the risk: benefit ratio still favours the drugs. Br Med J 1990, 300: 1668-1669.

19. Multiple Risk Factor Intervention Trial Group. Baseline rest electrocardiographic abnormalities, antihypertensive treatment, and mortality in the Multiple Risk Factor Intervention Trial. Am J Cardiol 1985, 55: 1-15.

20. Medical Research Council Working Party on Mild to Moderate Hypertension. Ventricular extrasystoles during thiazide treatment: substudy of MRC mild hypertension trial. Br Med J 1983, 287: 1249-1253.

21. Stewart, D.E., Ikram, H., Espiner, E.A. \& Nicholls, M.G. Arrhythmogenic potential of diuretic induced hypokalaemia in patients with mild hypertension and ischaemia heart disease. Br Heart J 1985, 54: 290-297.

22. Struthers, A.D., Reid, J.L., Whitesmith, R. \& Rodger, J.C. Effect of intravenous adrenaline on electrocardiogram, blood pressure, and serum potassium. Br Heart $J$ 1983, 49: 90-93.

23. Edwards, R., Winnie, A.P. \& Ramamurthy, S. Acute hypocapneic hypokalaemia: an iatrogenic anesthetic complication. Anesth Analg 1977, 56: 786-792.

24. Finsterer, U., Luhr, H.-G. \& Wirth, A.E. Effects of acute hypercapnia and hypocapnia on plasma and red cell potassium, blood lactate and base excess in man during anesthesia. Acta Anaesth Scand 1978, 22: 353-366.

25. Wong, K.C., Wetstone, D., Martin, W.E., Cheney, F. \& Wyte, S.R. Hypokalaemia during anesthesia: the effects of d-tubocurarine, gallamine, succinylcholine, thiopental, and halothane with or without respiratory alkalosis. Anesth Analg 1973, 52: 522-528. 
26. List, W.F. Serum potassium changes during induction of anaesthesia. Br J Anaesth 1967, 39: 480-484.

27. Dodd, R.B., Sims, W.A. \& Bone, D.J. Cardiac arrhythmias during anesthesia and surgery. Surgery 1962 51: 440-447.

28. Kuner, J., Enescu, V., Utsu, F., Boszormenyl, E., Bernstein, H. \& Corday, E. Cardiac arrhythmias during anesthesia. Dis Chest 1967, 52: 580-587.

29. Vanik, P.E. \& Davis, H.S. Cardiac arrhythmias during halothane anesthesia. Anesth Analg 1968, 47: 299-307.

30. Goldman, L., Caldera, D.L., Nussbaum, S.R. et al. Multifactorial index of cardiac risk in non cardiac surgical procedures. N Engl J Med 1977, 297: 845-850.

31. Katz, R.L. \& Bigger, J.T. Cardiac arrhythmias during anesthesia and operation. Anesthesiology 1970, 33: 193-213.
32. Glaser, R. Chronic hypokalaemia and intraoperative dysrhythmias. Anesthesiology 1986, 64: 408-409.

33. Vitez, T.S., Soper, L.E., Wong, K.C. \& Soper, P. Chronic hypokalaemia and intraoperative dysrhythmias. Anesthesiology 1985, 63: 130-133.

34. Hirsch, I.A., Tomlinson, D.L., Slogoff, S. \& Keats, A.S. The overstated risk of preoperative hypokalaemia. Anesth Analg 1988, 67: 131-136.

35. Vaughan, R.S. Potassium in the perioperative period. $\mathrm{Br} J$ Anaesth 1991, 67: 194-200.

36. McGovern, B. Hypokalaemia and cardiac arrhythmias. Anesthesiology 1985, 63: 127-129. 